\title{
Blood profile holds clues to role of infection in a premonitory state for idiopathic parkinsonism and of gastrointestinal infection in established disease
}

\author{
André Charlett ${ }^{1,2}$, R John Dobbs ${ }^{1,3}$, Sylvia M Dobbs*1,3, Clive Weller ${ }^{1}$, \\ Mohammad AA Ibrahim ${ }^{4}$, Tracy Dew ${ }^{5}$, Roy Sherwood ${ }^{5}$, Norman L Oxlade ${ }^{1}$, \\ J Malcolm Plant ${ }^{1}$, James Bowthorpe ${ }^{1}$, Andrew J Lawson ${ }^{6}$, Alan Curry ${ }^{7}$, \\ Dale $\mathrm{W}$ Peterson ${ }^{8}$ and Ingvar T Bjarnason ${ }^{3}$
}

Address: ${ }^{1}$ Therapeutics Research Group, Institute of Psychiatry at King's College London, London, UK, ${ }^{2}$ Statistics Unit, Health Protection Agency, London, UK, ${ }^{3}$ Department of Gastroenterology, King's College Hospital, London, UK, ${ }^{4}$ Department of Immunology, King's College Hospital, London, UK, ${ }^{5}$ Department of Biochemistry, King's College Hospital, London, UK, ${ }^{6}$ Laboratory of Gastrointestinal Pathogens, Health Protection Agency, London, UK, ${ }^{7}$ Electronmicroscopy, Health Protection Agency North West, Manchester, UK and ${ }^{8}$ School of Life Sciences, University of Hertfordshire, Hatfield, UK

Email: André Charlett - andre.charlett@hpa.org.uk; R John Dobbs - JohnDobbs@TherapeuticsResearch.net;

Sylvia M Dobbs* - sylviadobbs@therapeuticsresearch.net; Clive Weller - CliveWeller@TherapeuticsResearch.net;

Mohammad AA Ibrahim - m.ibrahim@kcl.ac.uk; Tracy Dew - tracy.dew@kch.nhs.uk; Roy Sherwood - roy.sherwood@kch.nhs.uk;

Norman L Oxlade - norman.oxlade@btinternet.com; J Malcolm Plant - Malcolm.Plant@kcl.ac.uk;

James Bowthorpe - James.Bowthorpe@kcl.ac.uk; Andrew J Lawson - andy.lawson@hpa.org.uk; Alan Curry - Alan.Curry@CMMC.nhs.uk;

Dale W Peterson - d.w.peterson@herts.ac.uk; Ingvar T Bjarnason - ingvar.bjarnason@kcl.ac.uk

* Corresponding author

Published: 26 November 2009

Gut Pathogens 2009, I:20 doi:10.1 I86/1757-4749-1-20

This article is available from: http://www.gutpathogens.com/content/l/I/20

(C) 2009 Charlett et al; licensee BioMed Central Ltd.

This is an Open Access article distributed under the terms of the Creative Commons Attribution License (http://creativecommons.org/licenses/by/2.0), which permits unrestricted use, distribution, and reproduction in any medium, provided the original work is properly cited.
Received: 14 October 2009

Accepted: 26 November 2009

\begin{abstract}
The two-stage neuroinflammatory process, containment and progression, proposed to underlie neurodegeneration may predicate on systemic inflammation arising from the gastrointestinal tract. Helicobacter infection has been described as one switch in the pathogenic-circuitry of idiopathic parkinsonism (IP): eradication modifies disease progression and marked deterioration accompanies eradication-failure. Moreover, serum Helicobacter-antibody-profile predicts presence, severity and progression of IP. Slow gastrointestinal-transit precedes IP-diagnosis and becomes increasinglyapparent after, predisposing to small-intestinal bacterial-overgrowth (SIBO). Although IP is welldescribed as a systemic illness with a long prodrome, there has been no comprehensive overview of the blood profile. Here, it is examined in relation to Helicobacter status and lactulose-hydrogenbreath-testing for SIBO.

A robust finding of reduced lymphocyte count in 126 IP-probands and 79 spouses (without clinically-definite IP), compared with that in $38 \mathrm{I}$ controls ( $P<0.00 \mathrm{I}$ in each case), was not explained by Helicobacter-status or breath-hydrogen. This complements a previous report that spouses were 'down-the-pathway' to 'clinically-definite' disease. In 205 other controls without clinically-definite IP, there were strong associations between sporadic cardinal features and immunoglobulin class concentration, not explained by Helicobacter-status. Premonitory states for idiopathic parkinsonism associated with relative lymphopenia, higher serum immunoglobulin concentrations and evidence of enteric-nervous-system damage may prove viral in origin.
\end{abstract}




\begin{abstract}
Although only $8 \%$ of the above 79 spouses were urea-breath-test-positive for Helicobacter, all 8 spouses with clinically-definite IP were $(p<0.000 \mathrm{I})$. Transmission of a 'primer' to a Helicobactercolonised recipient might result in progression to the diagnostic threshold.

Twenty-five percent of the 126 probands were seropositive for anti-nuclear autoantibody. In 20 probands, monitored before and serially after anti-Helicobacter therapy, seropositivity marked a severe hypokinetic response $(p=0.03)$. It may alert to continuing infection, even at low-density. Hyperhomocysteinemia is a risk factor for dementia and depression. Serum homocysteine exceeded the target in 43\% of the I 26 IP-probands. It was partially explained by serum BI2 (I2\% variance, $P<0.00 I$ ), but not by Helicobacter-status (gastric-atrophy uncommon in IP) or levodopa treatment. Immune-inflammatory activation increases homocysteine production. Since an estimated $60 \%$ of probands are hydrogen-breath-test positive, SIBO, with its increased bacterial utilisation of $\mathrm{BI2}$, is a likely cause. Thus, two prognostic indicators in established IP fit with involvement of Helicobacter and SIBO.
\end{abstract}

\section{Background}

It has been proposed [1] that, whatever the aetiological insult or affected brain area, a two-phase neuroinflammatory process, containment and progression, is common to neurodegenerative diseases. These two phases may predicate on systemic inflammation.

Whilst local brain inflammation does not usually signal out [2], systemic inflammation can communicate with the brain's immune system, by evading or compromising the blood brain barrier [1,3]. Idiopathic parkinsonism (IP) is associated, in small studies, with a lower blood lymphocyte count [4-7]. Morphological and neurochemical changes, characteristic of IP, are seen in the enteric nervous system [8,9]. IP also involves heart [10] and skin $[11,12]$, and endocrine $[13,14]$, metabolic $[15,16]$ and peripheral inflammatory processes $[13,17]$. There is a long prodrome [for review see [18]]. The 'infection hypothesis' for IP implicates the gut, the 'Helicobacter hypothesis' one player [18]. Slow gastrointestinal-transit precedes IP-diagnosis and becomes increasingly-apparent after $[19,20]$, predisposing to small-intestinal-bacterial-overgrowth (SIBO) [21]. The serum Helicobacter antibody immunoblot-profile predicts presence, severity and progression of IP [22]. Conversion of malignant IP to benign following Helicobacter eradication is reported, irrespective of presence of anti-parkinsonian medication [23,24]. Marked deterioration accompanied eradication-failure [23]. Attributing the benefit of Helicobacter eradication solely to levodopa absorption [25], ignores the effect in those not receiving this short $\mathrm{t} 1 / 2$ dopamine precursor, or, indeed, any anti-parkinsonian medication $[18,23]$.

Confirming relative lymphopenia in probands would indicate a xenobiotic, nutritional or infective influence, finding it in their spouses a shared insult in adult-life. In $\mathrm{IP}$, there is no convincing evidence of excessive exposure to xenobiotics, or of the relevance of genes regulating their metabolism [18]. There is no indication of malnutrition/ malabsorption, but increased energy expenditure may cause weight loss [24]. Regarding possible haematinic deficiency, peptic ulcer is prodromal [26]. Lymphopenia might result directly from chronic infection. $H$. pylori whole-bacteria, cell-fractions, culture-supernatants and protein-products, and $H$. pylori-specific regulatory T-lymphocytes inhibit human T-cell proliferation $[27,28]$. Moreover, a lower serum IgM is associated with Helicobacter-seropositivity [29], but whether the relationship holds in IP is unknown. Lymphopenia could result from autoimmunity, reversible by eradicating a trigger, as proposed in Helicobacter-associated idiopathic thrombocytopenic purpura (ITP) [30]. Indeed, antibody against a $H$. pylori virulence-factor, cytotoxicity-associated-gene (cagA) product, is implicated in ITP [30] and IP [22]. In the presence of SIBO, most IP-probands' duodenal enterocytes contain apparently hypertrophic mitochondria [18]: lymphocyte mitochondria might show similar morphological compensation for hypofunction [31].

We present the first comprehensive overview of the blood profile in IP in relation to indices of Helicobacter infection and hydrogen-breath-testing for SIBO. We consider definition of a 'premonitory' stage, potential markers of progression towards established disease and prognostic indicators within it. An aetiological/pathogenic solution may remain elusive without embracing limited manifestations in 'controls'.

\section{Methods \\ Patients and controls}

In phase-1 [22], we recruited consecutive patients with 'clinically-definite' IP [32], criteria as in Table 1 . There was a contemporaneous call for healthy controls without IP: those found to have 'clinically-possible or -probable' parkinsonism [32] (Table 1, footnote ${ }^{a}$ ) were not excluded. Other criteria were as shown for probands in the Table. Serum immunoglobulin concentrations were contrasted between 120 probands (12 men, 12 women per decade, 
Table I: Inclusion and exclusion criteria for probands.

\begin{tabular}{ll}
\hline Inclusion & \\
\hline I. & Independently-living subjects with clinically-definite ${ }^{\mathrm{a}}$ idiopathic parkinsonism \\
\hline 2. & Caucasian with English as first language and living in UK
\end{tabular}

\section{Exclusion}

I. Secondary parkinsonism, "parkinsonism-plus" syndromes and other wider clinical entities [32]

2. Clinical depression [64], dementia $[65,66]$, or other mental illness.

3. Other specific neurological condition

4. Exposure to specific antimicrobial/anti-secretory therapy against Helicobacter

5. Inflammatory bowel disease or history of major gastrointestinal surgery

6. Other progressive or resolving disorders affecting physical ability or performance ${ }^{c}$ or sufficient underlying incapacity to prevent assessments (e.g. use of walking aid)

7. Cardiovascular/respiratory symptoms during normal activities

8. UK MRC muscle strength score $<4 / 5$

9. Arthropathy, mucsulo-skeletal disorder or overt abnormalities of/history of orthopaedic surgery to joints of spine or lower limbs

I0. Concurrent therapy with drugs which might be anti-dopaminergic or with hypnotics or sedatives

II. Recent change in life situation (e.g. bereavement or change in marital status/domicile)

${ }^{a}$ Any combination of three of the cardinal features: resting tremor, rigidity, bradykinesia or impairment of postural reflexes. Alternatively sufficient two of the four features, with one of first three asymmetrical [32]. Responsiveness to a dopaminergic drug challenge not a requirement. Excluded were:-

- clinically-probable parkinsonism. Combination of any two cardinal features. Alternatively, asymmetrical resting tremor, rigidity, or bradykinesia sufficient.

- clinically-possible. Presence of any one: tremor, rigidity, or bradykinesia. Tremor must be of recent onset, may be postural or resting.

N.B. In controls in Phase I, presence/absence of following features $[53,67]$ judged (unilateral being sufficient) by two physicians:-

(i) hand bradykinesia* (obvious slowing pronation/supination).

(ii) rigidity* at rest and/or activation phenomenon (rigidity evoked by voluntary movement of contralateral limb).

(iii) rest tremor* and/or postural tremor (over a $20 \mathrm{~m}$ walk).

(iv) forward displacement of occiput after standing for I minute, with buttocks and heels against a wall (posture abnormal if distance $>10 \mathrm{~cm}$ ).

*evaluated in upper limbs, with seated subject's head, trunk and lower limbs screened.

bTo constrain ethnic and/or geographical influences.

cAssessments and blood sampling avoided during acute intercurrent illness.

$40-89$ years) and 205 controls ( $\geq 12$ each gender per decade, 30-89 years). The relationship of presence/absence of features of clinically-possible or -probable IP to concentration was explored in controls, as was that of a continuous measure of hypokinesia, mean-stride-length at freewaking-speed [33]. Any differential effect of Helicobacter anti-urease antibody-status was examined.

In phase-2 [23], we obtained first-visit full blood counts (FBC) from 118 other clinically-definite IP-probands (Table 1). These were contrasted with 381 routine FBCs from consecutive adults, requested by general practices from the same laboratory over the same period. Exclusions in these controls were limited to specified parkinsonism; haematological, immunological and malignant disorders; haemorrhage; and race other than Caucasian (see footnote ${ }^{b}$ ). FBCs from 87 accompanying spouses/ partners of probands were also studied, inclusive of clinically-possible/probable/definite IP (other criteria as for probands). Proband and 'spouse' lymphocyte subset data were contrasted with summary statistics (kit manufacturer's and published [34]) for haematologically-normal adult donors. The following were explored as determinants of FBC and subset profiles: serum haematinic and 
homocysteine concentrations (probands); serum autoantibody screen (probands); Helicobacter indices and results of hydrogen-breath-testing for SIBO (probands/spouses). In a subgroup, within-proband time-trends in cell counts (yearly sampling) were contrasted between the ureabreath-test (UBT) positive for Helicobacter infection and the UBT-negative, any impact of $H$. pylori eradication being noted. Any modifying effect of prevalent autoantibodies on the outcome of $H$. pylori eradication therapy was explored. This involved duplicate gait assessments on two baseline occasions and at $\geq 6$-weekly intervals posttherapy, any background anti-parkinsonian medication being constant, and usage of levodopa being an exclusion.

In both phases, any anti-parkinsonian medication and laxative use were recorded. Protocols had been approved by local ethics committees, written consent obtained from participants.

\section{Blood cellular profile}

Whole blood T-cell (CD3+), T-helper (CD4+), cytotoxic Tcell (CD8+), B-cell (CD19+), and natural-killer (NK) cell $(\mathrm{CD} 16+\mathrm{CD} 56+)$ counts were determined. The sum of the lymphocyte subsets was validated by reference to FBC lymphocyte count [35] (Figure 1).

\section{Serum haematinics and homocysteine}

Sera were stored at $-20^{\circ} \mathrm{C}$, and randomly allocated withinassay, with (except for Helicobacter serology, see below)

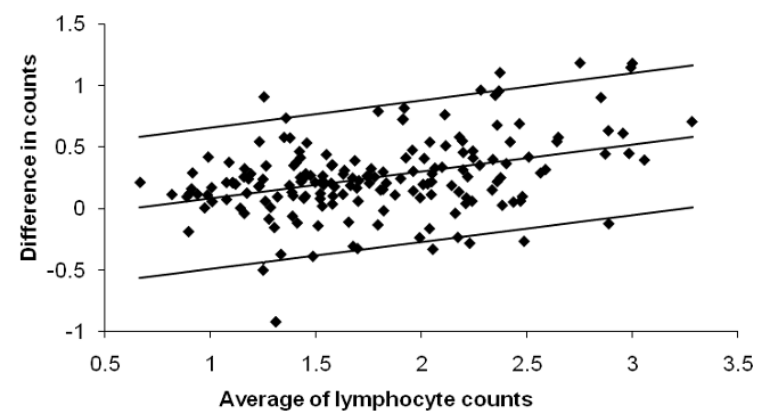

Figure I

Bland-Altman contrast of difference in and average of lymphocyte counts $(\times 109 / 1)$ by two methods in 163 subjects. Difference expressed as subset sum (CD3+, CD I9+ and CD 16+56+)* minus FBC value**. Regression line and $95 \%$ upper \& lower limits of agreement shown. Difference between subset sum and routine lymphocyte count is small around grand mean for average count, its variability constant over the range.

*Four-colour fluorescent cell labelling using the MultiTEST kit in TruCOUNT tubes and a FACSCalibur flow cytometer (Becton Dickinson, San Jose, California, USA).

** Using XE2 100, Sysmex UK Ltd., Wymbush. between-assay stratification for subject-group, age and gender.

Serum ferritin was measured by two-site sandwich immunoassay with two anti-ferritin antibodies; folate, vitamin B12, and homocysteine by competitive immunoassays, using direct chemiluminescence (Bayer Diagnostics Europe Ltd, Newbery, UK.) Inter-assay coefficients of variation (CV) were $2.7,4.2$ and $3.7 \%$ at $10.8,142.4$ and $929.6 \mu \mathrm{g} / \mathrm{l}$ ferritin, respectively; $6.11,7.19$ and $6.36 \%$ at $1.70,10.01$ and $14.95 \mu \mathrm{g} / \mathrm{l}$ folate; $9.2,2.7$ and $3.0 \%$ at $178.7,608.83$ and $1343.87 \mathrm{ng} / \mathrm{l} \mathrm{B12}$; and 5.2, 1.5 and $3.1 \%$ at $4.9,22.2$ and $61.6 \mu \mathrm{mol} / 1$ homocysteine.

\section{Serum immunoglobulin classes and autoantibodies}

Immunoglobulin classes were measured by immunoturbidity (Cobas Mira Plus, Roche Diagnostics Corp., Indianapolis, USA). Inter-assay CV was 6.5 and $4.9 \%$ at 7.5 and $11.6 \mathrm{~g} / \mathrm{l} \mathrm{IgG}$, respectively; 5.9 and $4.4 \%$ at 1.3 and $2.5 \mathrm{~g} / \mathrm{l}$ IgA; and 4.5 and $3.4 \%$ at 0.7 and $1.1 \mathrm{~g} / \mathrm{l}$ IgM. IgA subclasses were measured by radial immunodiffusion (Bind A Rid, Birmingham, UK): CV was $11 \%$ at $3360 \mathrm{mg} / \mathrm{lgA1}$; and $7.5 \%$ at $360 \mathrm{mg} / \mathrm{l} \mathrm{IgA2}$. Serum was screened for antinuclear, anti-smooth muscle, anti-mitochondrial, antigastric parietal cell and anti-liver/kidney microsomal antibodies. The additional autoantibodies listed, as well as the above, were sought before H. pylori eradication therapy and on average 11 /2 years after, in a subgroup: antineutrophil cytoplasmic (ANCA), anti-thyroid peroxidase, anti-adrenal, anti-tissue transglutaminase, anti-intrinsic factor, anti-acetylcholine receptor, anti-neuronal nuclear and anti-purkinje cell. For each assay, samples were processed in a single batch, blind to sequence.

\section{Helicobacter status}

Helicobacter-status was defined by:- (i) $\left[{ }^{13} \mathrm{C}\right]$ urea-breathtest (INFAI Ltd., York, UK). (ii) Enzyme-linked immunosorbent assay (ELISA) of IgG-antibody directed against cell-bound $H$. pylori urease (SIA417A, Delta Biologicals, Rome, Italy: seropositive 'ELISA-value' $>2.2$ ). Inter-assay CV was 13.0, 8.0 and $6.0 \%$ at ELISA-values $0.8,2.4$ and 5.9. (iii) Western Blotting for serum antibodies against $H$. pylori antigens (RIDA Helicobacter Blot IgG, Quadratech Diagnostics Ltd., Epsom, UK: score $>12$ positive for current infection, 11-12 equivocal, $<11$ negative, irrespective of band-density). Test and quality-control immunoblots were read using a smooth curve, fitted through distance/ molecular weight co-ordinates derived from the kit's developed-control strip. This identifies 11 bands: cagA product; vacuolating-toxin(Vac)A; urease-B; outer-membrane-protein; flagellin; those at 47, 33, 29, 28, 25 \& 19 $\mathrm{kDa}$. Magnifying strips optimized precision. Helicobacter serology was standardised between study phases by protocol, equipment and quality-control, using same investigator throughout. In phase 2, H. pylori infection was 
confirmed in probands by endoscopic-biopsy for histopathology, culture and molecular-microbiology [23], eradication judged by UBT and, wherever possible, repeat biopsies.

\section{Hydrogen-breath-test for small-intestinal-bacterial- overgrowth}

Hydrogen-breath-tests were carried out in UBT-negative probands and spouses, using a 25 g lactulose test-dose, following 24-hour deprivation of dairy products (and medicinal lactulose) and a breakfast of $250 \mathrm{ml}$ black tea/ coffee or water. Hydrogen concentrations were measured (Micro Medical Ltd., Rochester, UK) pre-dose and at 15 minute-intervals for 4 hours after. A prolonged test, with non-absorbable substrate, was used because of potentially impaired gastric-empting and intestinal-transit $[9,24]$. Breath-hydrogen/time curves [36,37] were not bimodally distributed between-subject. Within-subject, two distinct peaks, early and 'colonic', were not present. Summary outcomes were examined: 2 hour value; maximum-value between 15 and 120 minutes; linear increase over 2 hours, when trend was to peak. Correlation coefficients were high for all contrasts, the maximum-value selected for analysis.

\section{Statistical analysis}

'Contemporaneous' reference range limits, constructed from a measurement made in 400 controls, would have a small standard deviation (approximately 0.09s, where s is standard deviation in the measurement), and be only marginally larger (0.1s) using 200 measurements [38].

In phase-2, controls below age 46 years had anomalous age-trends in FBC indices: these (19, presumably relatively-ill, individuals) were excluded. Since phase- 2 controls were not subject to the rigorous inclusion/exclusion criteria of phase-1, their white cell counts were examined for evidence of distinct Gaussian distributions (e.g. a subgroup with a higher mean count, compatible with acute intercurrent infection). There was a tendency for two distributions to describe total white cell count better (Figure 2 ), but no evidence that a mixture of distributions provided a better fit for lymphocytes or neutrophils. Comparisons with a 'conventional' reference range allowed robustness of any shift in distribution between subjectgroups to be tested. Wilcoxon signed-rank test was used to assess a shift from the reference median, chi-square goodness-of-fit to test whether the expected $5 \%$ of measurements fell outside the range.

Many chronic diseases are multi-step and multi-factorial: explanatory models were used to examine between-group and within-subject differences in laboratory measurements. Potential confounding or effect-modifying variables were assessed, examining for interactions prior to direct effects.

Where indicated, logarithmic transformations were employed, to ensure validity of assumptions of normality
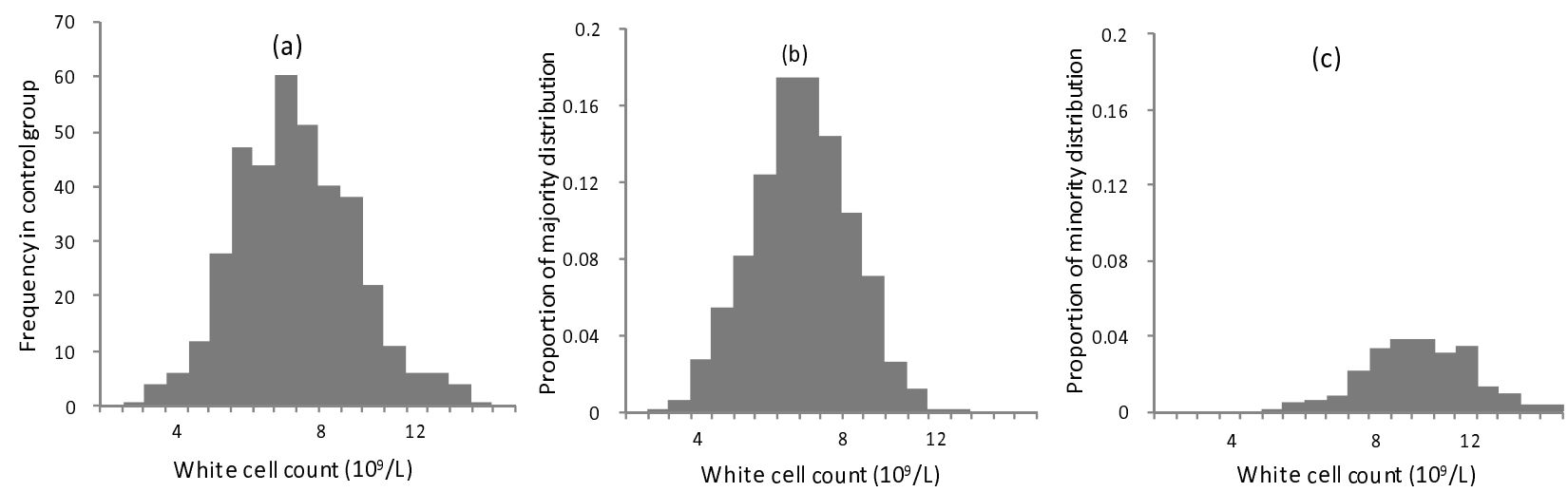

Figure 2

Distribution of total white cell count, and its decomposition into two Gaussian distributions. Histogram (a) shows $\log _{\mathrm{e}}$ transformed raw data. Histograms (b) and (c) are generated from parameter estimates obtained by applying a Gaussian mixture model to $\log _{e}$ (white cell count). They represent the 'best' mixture to replicate the overall distribution: i.e. two distributions tended to provided a better fit (likelihood ratio test, 3 degrees of freedom, $\chi^{2}=7.25, p=0.06$ ), (b) representing $80 \%$ of data, (c) a shift-to-the-right. There was no evidence that a mixture of Gaussian distributions provided a better fit to distribution of $\log _{e}$ transformed lymphocyte (age-corrected) or neutrophil counts $\left(\chi^{2}=0.74 \& 3.49, p=0.9 \& 0.3\right.$, respectively). 
of distribution and equality between groups of residual variance. The regression parameter for a log transformed outcome-variable was exponentiated, giving a relative (percentage) rather than absolute difference. That for a log transformed predictor was scaled by $1 / \log _{\mathrm{e}} 2$, so that a unit change reflected a doubling.

\section{Results \\ Full blood count}

Table 2 shows that the major differences in FBC of IPprobands (P) and their spouses (Ps) from controls (C) were in total lymphocyte count. Mean count was lower by 23.8 (95\% CI: 18.7, 28.7)\% in P and 17.3 (10.0, 24.0)\% in Ps ( $p<0.001$ in each case, age \& gender adjusted). Figure 3 shows the estimated proportion falling below the age-specific contemporaneous reference range: this was 12.5 (binomial exact 95\% CI: 7.2, 19.8)\% of P and 7.1 $(2.4,15.9) \%$ of Ps, compared with the $2.5 \%$ expected. No proband or spouse exceeded the range. The proportion falling below the lower limit of the conventional reference range $\left(1.3 \times 10^{9} / 1\right)$ was $30.8(22.7,39.9) \%$ of $\mathrm{P}, 10.0(4.1$, $19.5) \%$ of Ps and $7.3(4.9,10.4) \%$ of $C$, the frequency of 'lymphopenia' varying between groups (Pearson $\chi^{2}, \mathrm{p}<$ 0.001 ). In the $37.0 \%$ of probands never exposed to antiparkinsonian medication, mean lymphocyte count was 101.0 (95\% CI: 89.5, 113.9)\% of that in Ps, still significantly lower than in C. Exposure was associated with a $11.1(0.1,20.8) \%$ lower count $(\mathrm{p}=0.048)$, but inclusion of time-from-diagnosis (not important independently) reduced its significance to 0.1 . Thus, medication status and time-from-diagnosis were intrinsically linked, possibly surrogate for a more pertinent measure of disease.

Neutrophil polymorphonuclear count tended to be higher in $\mathrm{P}(\mathrm{p}=0.1$, gender adjusted) than in C. Haemoglobin concentration, red blood corpuscle count (RBC),

Table 2: Mean (95\% data interval) for full blood count indices in probands with idiopathic parkinsonism, their spouses and contemporaneous routine requests from primary care.

\begin{tabular}{|c|c|c|c|}
\hline & Probands** & Spouses $* * *$ & Controls \\
\hline Characteristic* & $(n=126)$ & $(n=79)$ & $(n=38 I)$ \\
\hline Age (years) & $60.8(41.0,80.5)$ & $59.4(37.2,81.6)$ & $58.4(37.6,79.1)$ \\
\hline Gender & $75 \mathrm{M}: 5 \mathrm{I} F$ & $23 \mathrm{M}: 56 \mathrm{~F}$ & $197 \mathrm{M}: 184 \mathrm{~F}$ \\
\hline Haemoglobin $(g / d l)$ male & $14.2(12.1,16.3)$ & $14.2(13.1,15.3)$ & $14.4(11.7,17.0)$ \\
\hline Haemoglobin $(\mathrm{g} / \mathrm{dl})$ female & I3.I (II.4, |4.8) & $13.2(\mid 1.7,14.8)$ & |3.| (II.0, 15.2) \\
\hline $\operatorname{RBC}\left(10^{12 / l}\right)$ male & $4.72(3.96,5.48)$ & $4.70(4.23,5.16)$ & $4.63(3.72,5.54)$ \\
\hline $\operatorname{RBC}\left(10^{12} / 1\right)$ female & $4.36(3.72,5.00)$ & $4.44(3.88,5.00)$ & $4.39(3.64,5.14)$ \\
\hline PCV male & $0.43(0.38,0.48)$ & $0.43(0.4,0.45)$ & $0.42(0.35,0.49)$ \\
\hline PCV female & $0.40(0.34,0.45)$ & $0.40(0.36,0.45)$ & $0.39(0.34,0.45)$ \\
\hline $\mathrm{MCV}(\mathrm{fl})$ & $91.35(84.04,98.66)$ & $90.99(83.24,98.74)$ & $90.91(80.94,100.87)$ \\
\hline $\mathrm{MCH}(\mathrm{pg})$ & $30.12(27.22,33.02)$ & $30.03(27.17,32.88)$ & 30.49 (26.4I, 34.57) \\
\hline $\mathrm{MCHC}(\mathrm{g} / \mathrm{dl})$ & $32.97(31.03,34.92)$ & $33.00(31.47,34.53)$ & 33.55 (31.50, 35.59) \\
\hline Platelets (109/l) & $240(151,382)$ & $244(154,386)$ & $242(142,4 \mid 2)$ \\
\hline White cell count $\left(10^{9} / \mathrm{I}\right)$ & $6.31(3.79,10.51)$ & $6.29(3.58,11.04)$ & $6.66(3.86,11.50)$ \\
\hline Neutrophils (109/I) & $3.95(1.93,8.08)$ & $3.78(1.90,7.53)$ & $3.69(1.77,7.66)$ \\
\hline Lymphocytes (109/I) & $1.52(0.78,2.97)$ & $1.71(0.93,3.12)$ & $2.05(1.09,3.88)$ \\
\hline
\end{tabular}

\footnotetext{
* Abbreviations specified in text.

** Presenting cases plus 8 spouses found to have clinically-definite IP. The latter tended $(p=0.07)$ to have a higher lymphocyte count.

**** Remaining spouses.
} 

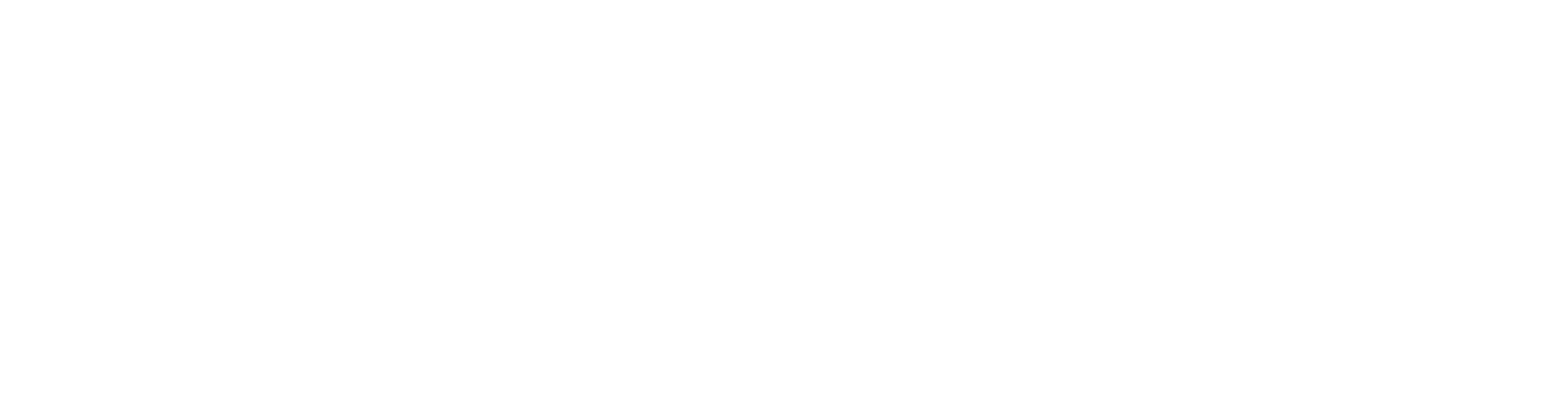

Figure 3

Contrast of lymphocyte counts $(\times 109 / 1)$ in probands with idiopathic parkinsonism and their spouses with an age-specific $95 \%$ reference range based on routine requests. Counts are corrected as if all subjects were male, using the relationship to gender in controls, there being no evidence of an age.gender interaction.

packed cell volume (PCV), mean corpuscular volume $(\mathrm{MCV})$, platelet count and mean platelet volume were not different in $\mathrm{P}$ or Ps from C. Mean corpuscular haemoglobin concentration (MCHC) was less in both than in $\mathrm{C}$, by small but highly significant amounts $(0.46(0.27$, $0.65) ; 0.33(0.09,0.58) \mathrm{g} / \mathrm{dl}$, respectively, $\mathrm{p}<0.001 \&=$ 0.008 , age and gender adjusted). Mean corpuscular haemoglobin $(\mathrm{MCH})$ tended to be less in $\mathrm{P}(\mathrm{p}=0.06)$.

\section{Lymphocyte subsets}

Subset counts in 106 of P and 70 Ps, expressed as a percentage of subset sum, are compared with the kit manufacturer's reference mean and 95\% confidence limits in Table 3 and Table 4 . Figure 4 summarises direction of effects. In P, CD4+ and CD8+ distributions were platykurtic, greater proportions than expected falling both above and below reference ranges. In Ps, there was a significant rightward shift in mean CD4+, and a significant leftward shift in CD8+ with respect to lower reference limit. A sig- nificant leftward shift in mean CD19+ was seen in both $P$ and Ps. That to-the-right in mean CD16+56+ characterised $\mathrm{P}$ alone. Subset shifts were not explained by anti-parkinsonian medication.

No difference in CD4+/CD8+ ratio was found between P and Ps, after adjustment for higher values with age $(\mathrm{p}=$ $0.001)$ and lower values in males $(\mathrm{p}=0.004)$. Overall, ratios complied with the inter-quartile reference range for gender by decade [34]. However, in younger males (41-50 years; $14 \mathrm{P}, 2 \mathrm{Ps})$, the mean ratio $(1.26(0.92,1.61))$ was markedly below the expected $2.29(\mathrm{p}<0.0001)$. In the 14 younger male probands, the lower the ratio, the higher the CD8+ count (adjusted r2 $=40 \%, \mathrm{p}=0.01$ ), but not the lower the CD4+.

Regarding within-couple concordance (70 pairs), CD3+, CD4+, CD8+ and CD19+ counts were lower in probands, by $14.2(2.0,24.9), 18.2(5.1,29.5), 17.1(2.1,29.8)$ and

Table 3: Comparison of percentage distribution of lymphocyte subsets in probands with idiopathic parkinsonism and their spouses with Multitest reference mean.

\begin{tabular}{llllllll}
\hline Subset & Reference mean & \multicolumn{3}{c}{ Probands } & Contrast with reference & Spouses & Contrast with reference \\
\cline { 2 - 9 } & \% subset sum & \% below & \% above & p-value* & \% below & \% above & p-value \\
\hline CD3+ & 72 & 42.5 & 57.5 & 0.5 & 28.1 & 71.9 & 0.0007 \\
\hline CD4+ & 45 & 45.3 & 54.7 & 0.09 & 24.6 & 75.4 & 0.0001 \\
\hline CD8+ & 24 & 59.4 & 40.6 & 0.06 & 52.6 & 47.4 & 0.3 \\
\hline CD 19+ & 13 & 67.9 & 32.1 & 0.0001 & 64.9 & 35.1 & 0.003 \\
\hline CD 16+56+ & 14 & 33.0 & 67.0 & 0.0001 & 63.2 & 36.8 & 0.2 \\
\hline
\end{tabular}

* Wilcoxon signed-rank test assuming reference mean $\equiv$ median.

For example: in probands, CD3+ subset conformed with reference mean value of $72 \%$ and range (see Table 4 ) of $56-86 \%$, in their spouses with range but not mean. 
Table 4: Comparison of percentage distribution of lymphocyte subsets in probands with idiopathic parkinsonism and their spouses with Multitest reference range.

\begin{tabular}{|c|c|c|c|c|c|c|c|c|c|}
\hline \multirow[t]{2}{*}{ Subset } & \multirow{2}{*}{$\begin{array}{l}\text { Reference range } \\
\% \text { subset sum }\end{array}$} & \multicolumn{3}{|c|}{ Probands } & \multirow{2}{*}{$\begin{array}{l}\text { Goodness of fit } \\
\text { p-value* }\end{array}$} & \multicolumn{3}{|c|}{ Spouses } & \multirow{2}{*}{$\begin{array}{l}\text { Goodness of fit } \\
\text { p-value }\end{array}$} \\
\hline & & \% below & $\%$ within & $\%$ above & & \% below & $\%$ within & $\%$ above & \\
\hline CD3+ & $56-86$ & 0.95 & 98.1 & 0.95 & 0.3 & 0.0 & 100.0 & 0.0 & 0.2 \\
\hline CD4+ & $33-58$ & 7.6 & 78.3 & 14.1 & 0.0001 & 1.8 & 80.7 & 17.5 & 0.0001 \\
\hline CD8+ & $13-39$ & 12.3 & 81.1 & 6.6 & 0.0001 & 8.8 & 86.0 & 5.2 & 0.004 \\
\hline CDI9+ & $5-22$ & 9.4 & 89.6 & 1.0 & 0.0001 & 1.7 & 96.5 & 1.8 & 0.9 \\
\hline CD $16+56+$ & $5-26$ & 0.0 & 91.5 & 8.5 & 0.0001 & 3.5 & 94.7 & 1.8 & 0.8 \\
\hline
\end{tabular}

*Pearson's $\chi^{2}$

$31.9(14.4,45.8) \%$ respectively (paired t-tests: $\mathrm{p}=0.03$, $0.01,0.03 \& 0.002)$. Probands' CD16+56+ count was higher by $23.6(7.7,42.0) \%(\mathrm{p}=0.004)$.

\section{Duodenal and lymphocyte mitochondria}

Figure 5 illustrates that the long thin duodenal enterocyte mitochondria found in IP are not necessarily associated with abnormal lymphocyte mitochondrial morphology.

\section{Serum haematinic and homocysteine concentrations}

Mean nutrient intakes were estimated from 3-day food diaries in 23 of the phase- 2 probands: they complied with UK National Reference Values.

In all 126 probands (Table 2), serum homocysteine was above the desired-maximum of $<16 \mu \mathrm{mol} / \mathrm{l}$ in 43.2 (binomial exact 95\% CI: 34.1, 52.7)\%. Figure 6 shows that the expected proportion had a serum B12 below reference range $(<180 \mathrm{ng} / \mathrm{l})$, but $16.1(10.0,24.0) \%$ had values within the 'equivocal range' (180-250 ng/l). The variance in homocysteine explained by B12 was only $12.1 \%$ (adjusted $\left.r^{2}, \mathrm{p}<0.001\right)$. Including relevant covariates, time-from-diagnosis $(\mathrm{p}=0.001)$ and gender $(\mathrm{p}=0.01)$ in the model increased variance explained to $27.0 \%, \mathrm{~B} 12$ maintaining its significance. Time-from-diagnosis was independent of age, which itself did not contribute to variance explained. Homocysteine was 1.8 (95\% CI: 0.8, $2.8) \%$ higher per year post-diagnosis, $12.5(2.5,22.5) \%$ higher in females.

Six percent of probands were both newly diagnosed and untreated: their median homocysteine concentration, $13.4 \mu \mathrm{mol} / \mathrm{l}$, was below the desired maximum. Receiving anti-parkinsonian medication other than levodopa
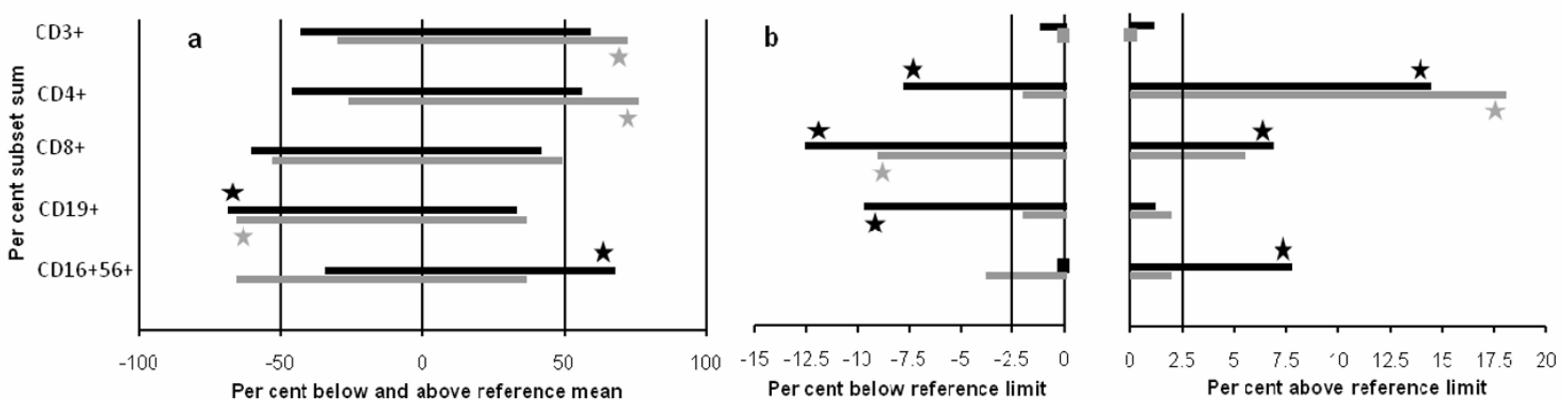

Figure 4

Shifts in percentage distribution of lymphocyte subsets in probands (P), with idiopathic parkinsonism, and their spouses (Ps) compared with reference range (a) mean and (b) its lower and upper reference limits. In $P$ (black bar) and Ps (grey bar), significant differences are denoted by black star and grey star, no subject outside reference limit by black square and grey square.

In (b), more than the $2.5 \%$ expected had CD4+ (in P), CD8+ (P \& Ps) and CD 19+ (P) below lower limit (exact binomial test: $P$ $\leq 0.01$ in each case), and CD4+ $(P \& P s), C D 8+(P)$ and $C D I 6+56+(P)$ above upper limit $(P \leq 0.02)$. 

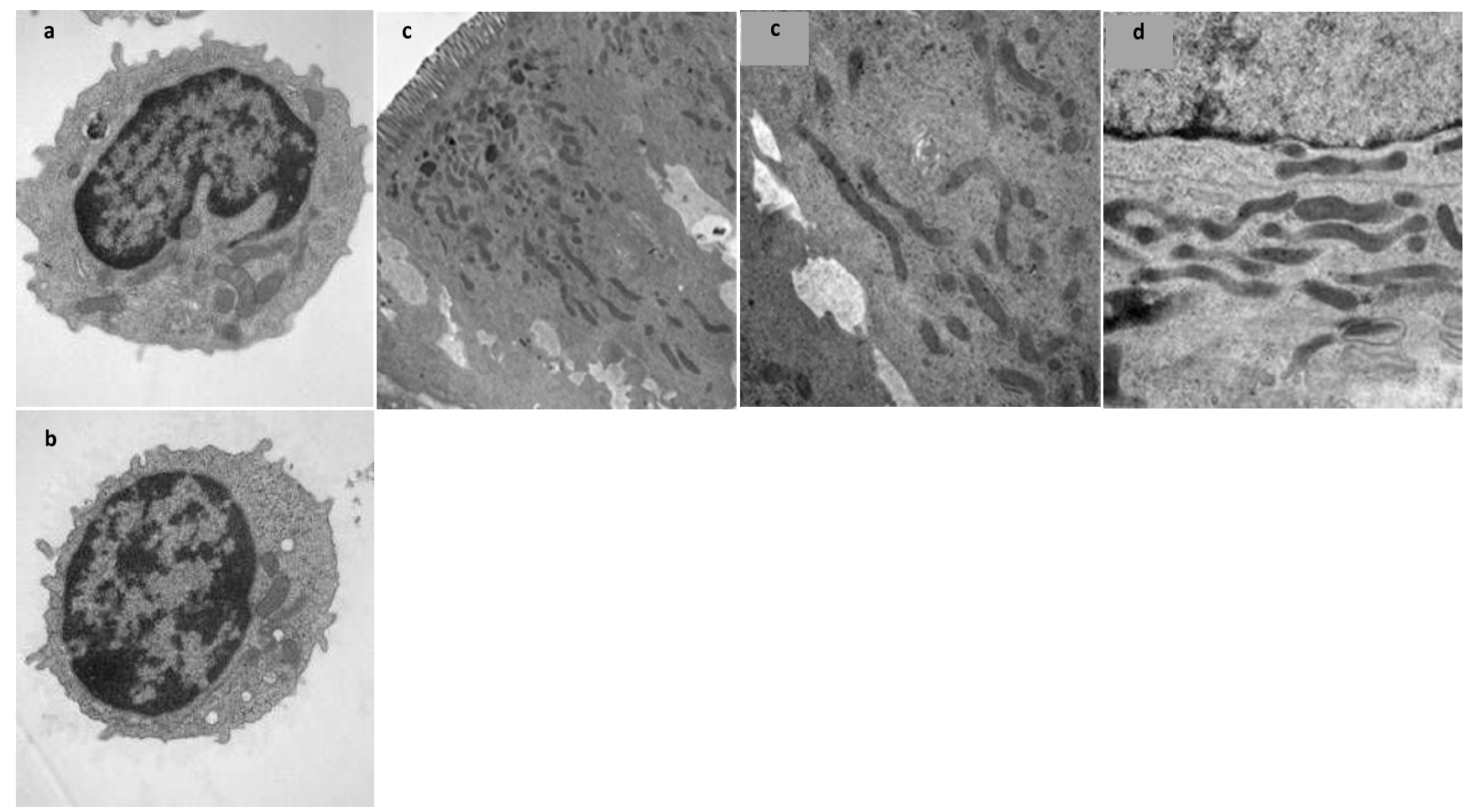

\section{Figure 5}

Lymphocyte and duodenal enterocyte ultrastructure in idiopathic parkinsonism (IP). Electron micrographs shows mitochondria in a representative blood lymphocyte from (a) a man with clinically-definite IP and (b) an age-matched healthy man, and in a representative duodenal enterocyte from (c) this IP-proband (panel to right shows higher magnification) and (d) his spouse. The proband's normal lymphocyte mitochondria are in marked contrast to his and his spouse's long thin duodenal mitochondria. The proband's IP had been diagnosed 7 years previously. He was receiving anti-parkinsonian medication. His spouse had probable-IP on screening. Both had bloating and cyclical diarrhoea going back 10 years. Typically, in the proband, 4 days of unformed stool alternated with constipation in a four-week cycle. In the spouse, explosive watery diarrhoea followed abdominal cramps, over 2 days in 2 week cycles, with normal bowel habit in between. Both had a positive hydrogen-breath-test (criterion: two consecutive values [37] >cut-point of meter manufacturer), and were negative for Helicobacter by UBT, serology, and culture/molecular microbiology on gastric biopsy.

(40.3\%) was not associated with increased homocysteine, compared with being untreated (37.0\%). Probands receiving levodopa $(22.7 \%)$ had a median total daily dose of 300 (interquartile range 300, 450) mg), a mean timefrom-diagnosis of 7 years. Their homocysteine was higher than in the remainder by 24.2 (95\% CI: 9.6, 40.8)\% (p = 0.001 , adjusted for B12 \& gender). However, exposure to levodopa was intrinsically linked to time-from-diagnosis, and the estimated 7-year increase in homocysteine for probands never exposed to levodopa $(19.6(7.7,31.6) \%)$ was comparable.

Probands' serum folate distribution was platykurtic, 7.6 (binomial exact 95\% CI: 3.5, 14.0)\% having concentrations above the reference range (3-13 $\mu \mathrm{g} / \mathrm{l}), 13.6$ (8.0, $21.1) \%$ below. Variance in homocysteine explained by folate ( $\mathrm{p}=0.007$ ) increased from 6.1 to $21.0 \%$ by including time-from-diagnosis $(\mathrm{p}<0.001)$ and gender $(\mathrm{p}=$ 0.005 ) in the model, but the significance of folate decreased to 0.1 . Folate did not contribute to variance explained by B12, gender and time-from-diagnosis.

Serum ferritin was below the reference range (20-300 $\mu \mathrm{g} /$ 1 males; $20-200 \mu \mathrm{g} / \mathrm{l}$ post-menopausal females) in 6.8 $(3.0,12.9) \%$. It contributed to explaining probands' MCHC and MCH: estimated increase of 0.17 (95\% CI: $0.01,0.33) \mathrm{g} / \mathrm{dl}$ in MCHC and $0.30(0.06,0.54) \mathrm{pg}$ in $\mathrm{MCH}$ with a doubling of ferritin $(\mathrm{p}=0.04 \& 0.02$, respectively).

Neither homocysteine nor these haematinics contributed to explaining total lymphocyte count in IP.

\section{Prevalence of autoantibodies}

Anti-nuclear antibody (ANA) was present in $25.3 \%$ of the 126 phase-2 probands, anti-intrinsic factor in $15.1 \%$, and anti-gastric parietal cell in 7.6\%. Gastric autoantibodies were not associated with a lower serum B12. Anti-smooth 


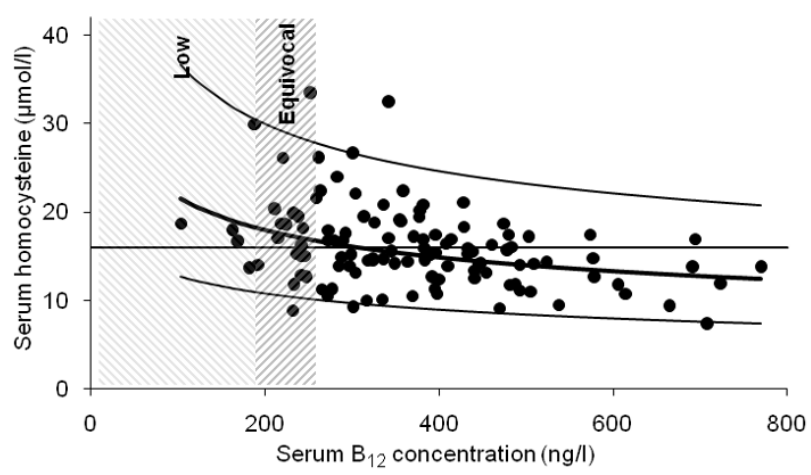

Figure 6

Relationship of serum homocysteine to B I 2 concentration in idiopathic parkinsonism. Two probands with exceptionally high homocysteine (I I 0 and I $35 \mu \mathrm{mol} / \mathrm{l})$ are excluded: the first had a low BI2 but normal folate, the second (with frank $H$. pylori infection and an empyema) a low folate with a normal BI2. Neither had received levodopa.

muscle antibody was present in $2.6 \%$, anti-mitochondrial and anti-liver/kidney microsomal negative throughout. In the more comprehensive screen in 21 probands, ANCA was present in 3, but none had antibodies against mye- loperoxidase or proteinase-3 targets. Total lymphocyte count was not associated with autoantibody-status.

\section{Serum immunoglobulin class concentrations}

Table 5 shows that, in phase-1, serum immunoglobulin concentrations in the 120 IP-probands and 205 contemporaneous controls were similar.

Figure 7 shows that presence, in controls, of hand-bradykinesia (16\%), or postural abnormality (9\%), was very strongly associated with a higher IgG and IgA. Stridelength was shorter by 59.3 (95\% CI: 1.9, 116.8) $\mathrm{mm}$ if IgG concentration doubled $(\mathrm{p}=0.04)$, but gait was not associated with IgA. Resting rigidity in arms was rare (1\%), but rigidity evoked by movement of the contralateral limb, the activation phenomenon, common (70\%) and associated with IgA (Figure 7 footnote). Resting tremor was also rare $(1.5 \%)$, postural tremor common (48\%) but not associated with immunoglobulin classes. Of these features, only hand-bradykinesia was associated with IgM, by contrast a strong negative relationship. All associations with IgA were attributable to IgA1.

Immunoglobulin concentrations, in probands, were unrelated to the presence/absence of a cardinal feature or stride-length. Concentrations were not associated with

Table 5: Serum immunoglobulin concentrations in probands with idiopathic parkinsonism and controls.

\begin{tabular}{|c|c|c|c|}
\hline \multirow[t]{3}{*}{ Serum concentration } & \multicolumn{2}{|c|}{ Geometric mean (95\% data interval) ${ }^{a}$} & \multirow{3}{*}{ Covariates $^{b}$} \\
\hline & \multirow{2}{*}{$\begin{array}{l}\text { Probands } \\
n=\mid 20\end{array}$} & \multirow{2}{*}{$\begin{array}{l}\text { Controls } \\
n=205\end{array}$} & \\
\hline & & & \\
\hline $\lg M(g / l)$ & $0.92(0.30,2.79)$ & $0.90(0.24,3.35)$ & age, Helicobacter status* \\
\hline $\lg G(g / l)$ & $11.39(6.11,21.21)$ & $11.92(7.33,19.39)$ & gender** \\
\hline $\lg A(g / l)$ & $2.95(1.12,7.79)$ & $3.13(1.15,8.46)$ & age, gender*** \\
\hline $\lg \mathrm{A} \mid(\mathrm{mg} / \mathrm{l})$ & $1574(538,4606)$ & $1652(569,4797)$ & \\
\hline $\lg \mathrm{A} 2(\mathrm{mg} / \mathrm{l})$ & $406(106,1557)$ & $388(97,1552)$ & \\
\hline \multicolumn{4}{|c|}{ 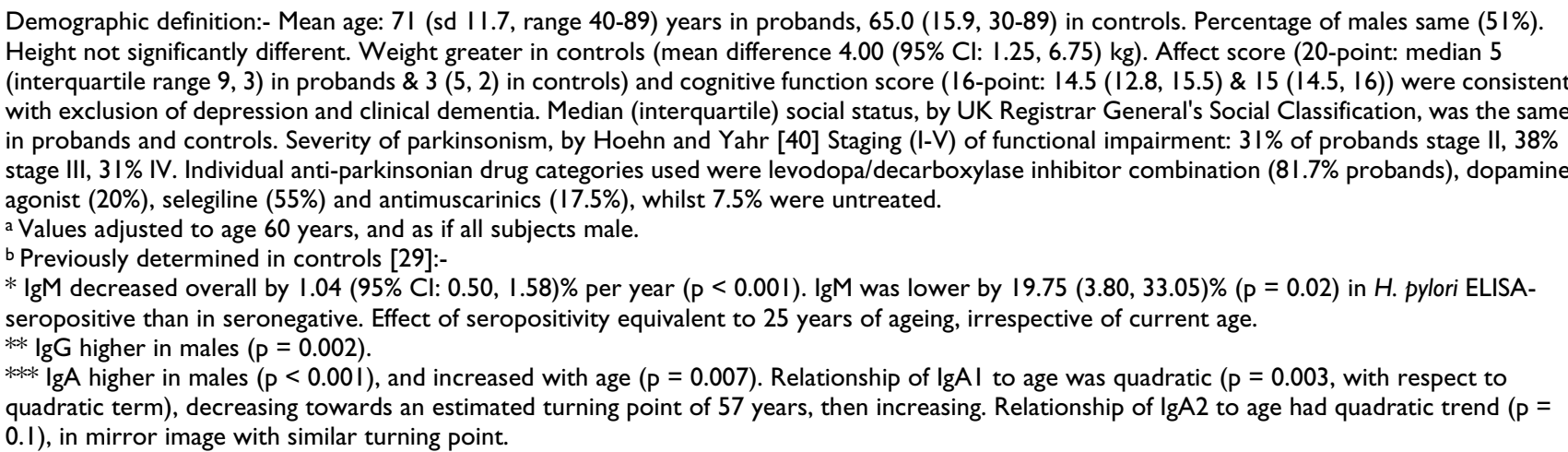 } \\
\hline
\end{tabular}




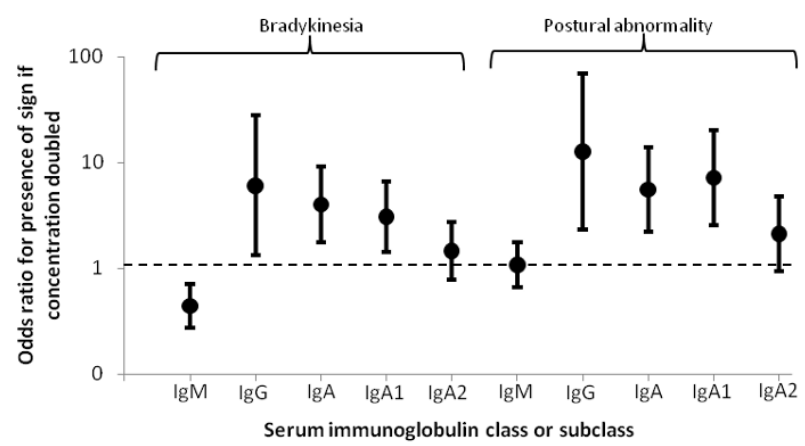

Figure 7

Estimated odds ratio, with $95 \% \mathrm{CI}$, in subjects without clinically-definite parkinsonism, for presence of a given sign, if serum immunoglobulin concentration doubled. Concentrations adjusted to age 60 years and as if all subjects male. Statistical significance of associations with bradykinesia and postural abnormality are, for $\lg M p=0.00 \mathrm{I}$ \& 0.8; for IgG 0.02 \& 0.003; for $\operatorname{lgA} 0.001$ \& 0.001 ; for $\operatorname{lgA} I$ $0.004 \& 0.001$; for IgA2 $0.2 \& 0.07$, respectively. Regarding rigidity, presence of activation phenomenon associated with $\operatorname{IgA}(\mathrm{OR}=\mathrm{I} .7(\mathrm{I} . \mathrm{I}, 2.6), \mathrm{p}=0.0 \mathrm{I})$ and $\lg \mathrm{AI}(\mathrm{I} .6(\mathrm{I} . \mathrm{I}, 2.3), \mathrm{p}=$ $0.02)$.

any class of dopaminergic medication. However, constipation, as denoted by regular laxative use (22 of the 100 probands so questioned), was associated with increased IgA (odds ratio $2.1(1.03,4.4)$ for concentration being double if taking medication, $\mathrm{p}=0.04)$. Antimuscarinics can, of course, constipate: the odds ratio remained similar $(2.30(1.23,4.33), \mathrm{p}=0.01)$ when antimuscarinic use $(14$ more probands) was also taken to denote constipation. Again, relationships depended on IgA1.

\section{Helicobacter-status of spouses and probands}

Crude prevalence rate estimates for 'Parkinson's disease' in 34 European studies range widely, from 65.6 to 12,500 per 100,000 [39]. The estimate lay within the binomial exact $95 \%$ CI for the spouse cohort $(9,195 \quad(4,045$, $17,317)$ per 100,000$)$ in only one study. All 8 spouses with clinically-definite IP had 'frank' UBT-positive Helicobacter infection, only $8 \%$ of the other spouses did $(P<$ $0.0001)$. Table 6 shows that frequency of positive Helicobacter-status, by breath-test or serology, tended to be less in the spouse cohort than in presenting cases.

In the earlier IP-cohort, prevalence of seropositivity was not significantly different from that in the socially-similar controls (Table 6). The odds of a proband's sample being immunoblot-positive and ELISA-negative, compared with vice versa, became 69.1(95\% CI: 4.9, 978.3) times greater in phase- 2 than, 10 year earlier, in phase- $1(p=0.02)$. In the later IP-cohort, ELISA-positivity was shown to repre- sented frank infection, in that its prevalence concurred with that of UBT-positivity.

\section{Helicobacter and blood profile Cellular profile}

In the later IP-cohort and their spouses (Table 6), UBTpositivity was not associated with total lymphocyte count (nor was ELISA-positivity). However, the CD8+ subset count was higher with frank infection by 27.8 (6.1, $53.9) \%$, ( $p=0.01$, age adjusted: no interaction between presence/absence clinically-definite IP and Helicobacterstatus, nor any direct disease-status effect). Immunoblotpositivity was much more frequent and associated with a higher total lymphocyte count (by $11.9(2.2,21.7) \%, \mathrm{p}=$ 0.02 , age \& gender adjusted). Even an equivocal immunoblot score tended to be $(16.3(-1.4,33.9) \%, \mathrm{p}=0.07)$. Of the 11 bands sought, only anti-VacA (39.4\%) was relevant to total count $(\mathrm{p}=0.01)$. A positive/equivocal immunoblot was associated with a higher CD3+ count $(\mathrm{p}=0.03)$. It was associated with a higher CD19+ count only in the presence of frank infection (immunoblot-status.UBT-status interaction, $\mathrm{p}=0.01)$. The CD16+56+ count was not associated with Helicobacter-status.

With UBT-positivity, platelet count was higher (9.2 (1.2, $17.8) \%, \mathrm{p}=0.02$, gender adjusted) and serum folate lower (25.2 (7.9, 39.2)\%, $\mathrm{p}=0.007$ : measured in probands only). This is compatible with bleeding and gastritis. However, MCHC and serum ferritin were not associated with Helicobacter-status, neither were B12 and homocysteine.

Serial lymphocyte counts were obtained in 49 probands (203 observations, median 4 (interquartile range 3, 5), over $2.6(2.1,3.5)$ years), counts were stable in the 21 without frank infection. However, following biopsyproven $H$. pylori eradication in 28 , lymphocyte count did tend to increase $(3.6$ (95\% CI: $0.0,7.8) \%$ per year, $\mathrm{p}=$ $0.08)$, there being no prior time-trend.

\section{Autoantibody-status}

Neither UBT- nor immunoblot-status influenced the frequency of ANA, the most common autoantibody found in clinically-definite IP.

Of 21 biopsy-positive probands, screened for autoantibodies in relation of anti-H. pylori therapy, ANA was present in 8 before, 10 after. Eradication failed in $6(2$ UBT-positive, 4 biopsy-positive only), of whom 5 were ANA-positive afterwards: ANA tended to mark continuing infection $(\mathrm{p}=0.06)$. Change in mean stride-length following therapy was measured in 20 of 21 , over a median of 358 (interquartile range 148, 498) days with $11(8,20)$ paired assessments. Stride-length deteriorated markedly in the ANA-positive (by 149 (95\% CI: 13, 284) mm/year), 
Table 6: Comparison of prevalences of Helicobacter-positivity, by urea-breath-test (UBT) and serology, between probands with idiopathic parkinsonism and their spouses and controls.

\begin{tabular}{|c|c|c|c|c|c|c|}
\hline \multirow{3}{*}{ Test } & \multicolumn{6}{|c|}{ Helicobacter-positivity (\%) } \\
\hline & \multicolumn{2}{|c|}{ Probands } & \multicolumn{2}{|c|}{ Spouses } & \multicolumn{2}{|c|}{ Controls } \\
\hline & Phase-It & Phase-2†† & Phase-I & Phase-2†† & Phase-I† & Phase-2 \\
\hline & $n=120$ & $n=118$ & & $n=86^{a}$ & $n=196^{b}$ & \\
\hline UBT & - & 29.6 & - & 16.9 & - & - \\
\hline ELISA & 47.6 & 34.5 & - & 18.4 & 39.5 & - \\
\hline Immunoblot ${ }^{c}$ & 36.7 & 50.0 & - & 34.2 & 30.8 & - \\
\hline
\end{tabular}

aincluding 8 with clinically-definite IP.

bwithout clinically-definite IP.

cequivocal score in a further $8.2 \%$ of Phase 2 subjects.

† prevalence of seropositivity not significantly different. Both ELISA and immunoblot available in 196 of 205 controls.

†† $p=0.1,0.06 \& 0.06$ (age \& gender adjusted) for comparison of prevalence of positive-status by UBT, ELISA \& immunoblot, respectively.

N.B. Absolute change in prevalence of Helicobacter not addressed since IP-cohorts not matched for locality/social class.

in contrast $(\mathrm{p}=0.03)$ to improvement in the ANA-negative $(77(-1,156) \mathrm{mm} /$ year $)$. Anti-nuclear antibody appeared to mark a poor prognosis, but effects of ANAstatus and success/failure of eradication on stride-length were intrinsically linked. A lower CD8+ or double-positive $\mathrm{CD} 4+\mathrm{CD} 8+$ count was also associated with deterioration in stride-length $(\mathrm{p}=0.02,0.03$ respectively, age/ gender adjusted as appropriate), and tended to be with eradication failure ( $p=0.06,0.04)$. Indeed, a lower CD8+ count appeared linked with ANA-positivity $(p=0.07)$. Neither CD16+56+ count nor serum homocysteine were prognostic indicators in this context.

\section{Immunoglobulin class concentrations}

Serum IgM concentration was lower with ELISA-positivity in phase-1 controls (Table 5, footnote), but not in clinically-definite IP ( $\mathrm{p}=0.02$, for subject group.Helicobacterstatus interaction). This interaction also obtained when Helicobacter-status was defined by the immunoblot, in particular by the presence/absence of a single ( $47 \mathrm{kDa})$ band $(p=0.008)$. Notably, the same band explained the immunoblot association with IgM in controls $(\mathrm{p}=0.001)$. There was no evidence that other infections, consequent on functional impairment, were responsible: IgM was not higher the greater the Hoehn and Yahr Staging of IP [40]. No effect of subject group on other immunoglobulin classes was found, relative to Helicobacter serology or directly.

In controls, Helicobacter serology explained neither the relationship of features of clinically-possible/probable IP to immunoglobulin concentration (Figure 7) nor their presence directly.

\section{Small-intestinal bacterial-overgrowth and blood profile}

Maximum breath-hydrogen between 15 and 120 minutes (median 41 (interquartile range 17-73) ppm) was not influenced by age, gender or subject group (40 probands,
15 spouses without clinically-definite IP, in phase-2). The meter manufacturer's diagnostic cut-point (20 ppm increment) was exceeded at least once within the 2 hours in $65 \%$ (irrespective of subject-group), by two consecutive readings [37] in $60 \%$.

Although the maximum was not associated with total lymphocyte count, it was with the CD4+ subset count (estimated increase 9.2 (95\% CI: 1.2, 17.8)\% with a doubling of breath-hydrogen, $\mathrm{p}=0.03$, gender-adjusted, irrespective of subject group). It contributed to explaining probands' serum ferritin, and MCHC in probands and spouses (estimated decreases of $20.2(8.5,30.4) \%$ in ferritin and $0.20(0.02,0.39) \mathrm{g} / \mathrm{dl}$ in MCHC with a doubling of breath-hydrogen, $\mathrm{p}=0.03 \& 0.02$, respectively). Probands' folate, B12, homocysteine and autoantibodystatus were unrelated to maximum breath-hydrogen. Probands' and spouses' CD4+/CD8+ ratios were not explained by breath-hydrogen (nor UBT-status or immunoblot-status).

Helicobacter infection appeared to keep SIBO at bay. Breath-hydrogen was higher (Spearman rank correlation, $\mathrm{p}=0.003$ ) in those of the currently UBT-negative probands and spouses who had been UBT-positive on presentation. It tended to be higher $(\mathrm{p}=0.06)$ where the immunoblot score had been positive/equivocal. Hydrogen-breath-tests were performed, in two subsequent probands, before and serially after biopsy-proven eradication of Helicobacter (initially detected by molecular-microbiology on two culture-negative biopsies). One had become positive (two consecutive values criterion) at 8 months, the other converted between 12 and 18 months: even low-density infection appeared protective.

\section{Discussion}

Table 7 summarises individual clues yielded from the blood profiling with reference to a 'premonitory' stage, 
and prognostic indicators within established IP. Corresponding roles for pathogens in the evolution are postulated on the basis of the background, results and discussion below.

Reduced total lymphocyte count in clinically-definite IPprobands (even when never exposed to anti-parkinsonian medication) and their spouses is a robust finding. Suppression of T-cell proliferation by Helicobacter $[27,28]$ does not appear responsible. There was no cross-sectional association between lymphocyte counts and Helicobacterstatus, although probands' total count tended to increase following eradication. No relationship was found between total count and hydrogen-breath-test result, but the impact of SIBO eradication/reacquisition was not investigated. Generalised autoantibody seropositivity would have supported an autoimmune pathogenesis for IP: its absence cannot exclude. Whilst dysfunction of lymphocyte mitochondria is reported in IP [31], they do not necessarily exhibit the abnormal morphology seen in enterocytes. Haematinics, or immuno-inflammatory activation as flagged by homocysteine [41], did not account for the reduced total count.

Unexplained reduction in lymphocyte count and prodromal enteric-nervous-system damage $[19,20]$ might be viral in origin. Whereas ascent via gastrointestinal neural pathways [8] would fit with 'cold neurodegeneration', dissemination in blood could explain constitutional symptoms and widespread pathology. B-cells could be a target (as with Epstein-Barr virus): their proportion was reduced in spouses, more so in probands. Natural-killer cells provide first-line viral defence [42]. Probands had an increased proportion, whereas spouses had an increase in CD4+. Given the same insult, this suggests a difference in immune competence/regulation. Cytotoxic T-cells have an important role in eliminating virus-infected cells. Their platykurtic proportional distribution in probands may encompass an increase in earlier stages (as in asymptomatic human immunodeficiency virus, HIV, infection) and suppression in later stages (as in acquired immunodeficiency syndrome, AIDS). A low CD4+/CD8+ ratio can flag viral infection, classically HIV [34], and has been reported in IP $[4,5]$. Here, addressing age/gender covariates, it was low only in younger male probands and spouses.

We have classified intracellular microbial targets in IP for current diagnostic assays [18]. These include enteroviruses, which infect via the gastrointestinal tract and can have neurological consequences. In post-poliomyelitis syndrome, there is systemic illness with raised serum inflammatory markers, and metabolic and skin involvement [43-45]. Parkinsonism is reported [46], lymphopenia not. The century-old proposal linking poliomyelitis with motor-neurone disease has been updated to encompass subclinical infection [47]. Increasing mortality from motor-neurone disease, where vaccination has triumphed over clinical poliomyelitis [48], does not preclude this. Searching for undiscovered viruses requires leads. The epi-

Table 7: Summary of clues from blood profile to role of infection in aetiology/pathogenesis of idiopathic parkinsonism.

\begin{tabular}{|c|c|c|}
\hline Blood element & Clue & Postulate \\
\hline Blood lymphocyte count & $\begin{array}{l}\text { Reduced count in probands and their spouses } \\
\text { cf contemporaneous controls. }\end{array}$ & \\
\hline $\begin{array}{l}\text { Serum Immunoglobulin (IgM, IgG, IgA) } \\
\text { concentrations }\end{array}$ & $\begin{array}{l}\text { Strong associations with sporadic cardinal } \\
\text { features of parkinsonism in controls suggest } \\
\text { premonitory infection. }\end{array}$ & \\
\hline
\end{tabular}

Serum IgM concentration
Differential effect of Helicobacter seropositivity between probands and controls.

Sequestration to site gastric inflammation no longer obtains in established parkinsonism or there is increased production of poly-specific IgM (in response to Helicobacter or SIBO).

Autoimmune element to response to Helicobacter in probands. Hence, importance of residual low-density infection.

ANA associated with failure of, and functional deterioration after, Helicobacter eradication therapy in probands.
Immunoinflammatory activation likely cause. Importance of SIBO suggested by association of breath-hydrogen with iron absorption (ferritin \& $\mathrm{MCHC}$ markers) in a setting where moderate/severe gastric atrophy uncommon. Reduction of gastric acid by inflammatory cytokine likely mechanism. 
demiology of IP and HIV are distinct, but parkinsonism is seen in uncomplicated HIV-infection (not just with opportunistic infections in AIDS), and jejunal autonomic denervation described [18]. Thus a relatively benign retrovirus might explain the lymphocyte profile and predisposition to SIBO in IP-probands and spouses.

The relative lymphopenia in spouses complements our finding of marked differences (physiological/psychomotor/dermatological) relevant to parkinsonism between spouses, cohabiting with probands for half-a-century, and control couples $[12,33,49,50]$. Those spouses were, on average, a short, albeit highly significant, 'distance-downthe-pathway'. Their multifarious manifestations are difficult to dismiss as selective mating or learned/reactive behaviour. Here, both probands and spouses had a high frequency of hydrogen-breath-test-positivity. Indeed, we have estimated that $53 \%$ of probands and $36 \%$ of spouses have chronic bowel dysfunction by stringent definition [51]. Seven percent of probands, $14 \%$ of spouses have diarrhoea (unformed stool during $\geq 3 / 4$ past year, plus $\geq 3$ bowel movements/day for $1 / 2$ ). Greater enteric ( \pm vagal nucleus) neuronal damage in probands may stave-off a diarrhoeal response to SIBO. The implication is of a 'premonitory' stage in spouses, alone lacking impetus to reach the diagnostic threshold. Lack of within-couple concordance in Helicobacter-status between probands and spouses [23] suggests that any 'conjugally-transmitted primer' is not Helicobacter. However, transmission of a 'primer' to a Helicobacter-colonised recipient may result in progression to the diagnostic threshold. Both might be necessary, neither sufficient. Indeed, here, spouses had a relatively high prevalence of clinically-definite IP, and all so affected had frank Helicobacter infection. Persistence and burden of Helicobacter in established IP are discussed below.

Strong associations of sporadic cardinal features of parkinsonism with changes in circulating immunoglobulins also indicate a premonitory active process. That IgA associations were accounted for by IgA1 may indicate a bone marrow response, but does not exclude a mucosal [52]. The apparent link of constipation with IgA1 in probands suggests the latter. Frequency of defaecation begins to deviate from that of controls three decades before the median age of neurological diagnosis [20]. Moreover, a higher IgA1 was associated with activation of rigidity, a common sign in our controls, which enables "one to detect Parkinson's disease in its earliest phase" [53]. Helicobacter serology did not explain immunoglobulin associations, a virus and/or SIBO might. We describe a differential IgM response to Helicobacter between controls and probands. In IP, sequestration to the site of inflammation may no longer obtain, or there be increased production of poly-specific IgM by naïve-B- or B1-cells, despite the lower overall proportion of B-cells.
Hyperhomocysteinemia is associated with cardiovascular risk and conditions which overlap with parkinsonism: dementing illnesses [54] and depression [55]. Moderate elevation of homocysteine in nearly half of the IPprobands was explained only in small part by serum B12, with no complementary effect of folate. Hyperhomocysteinemia was unrelated to Helicobacter-status: absence of even moderate atrophy characterizes Helicobacter-associated gastritis in IP. [23,24]. The underlying cause is likely to be SIBO, in which there is increased bacterial utilisation of B12. We propose that consequent immunoinflammatory activation drives homocysteine production [41]. Activation may increase demand for B12, such that a concentration in the 'equivocal' range should be regarded as pathological. An inflammatory response to SIBO would fit with the inverse association between breath-hydrogen and indicators of iron-absorption. Interleukin-1 $\beta$, for example, acts centrally, as well as on gastric receptors, to inhibit acid secretion and hence iron-absorption [56]. Indeed, exploratory studies suggest a greater prevalence in IP of cytokine-gene polymorphisms predisposing to an intense innate inflammatory response [57]. Suppression of inflammation can reduce homocysteine effectively in rheumatoid arthritis [41], but this approach is precluded where the source is infection. In IP, eradication of SIBO for several years is feasible, where adequate gastrointestinal-transit can be maintained by sufficient fluid-intake, a high-fibre diet and bulk/osmotic laxatives [18].

There is no evidence that hyperhomocysteinemia in IP is genetically determined [58]. Cognitive impairment, clinical depression, other physical incapacity and cardiovascular symptoms were exclusions [54,55]. Hyperhomocysteinemia has been attributed to levodopa: its O-methylation by catechol-O-methyltransferase (COMT) can provide a substrate for homocysteine synthesis [59]. We clearly demonstrate that the only relevance of levodopa (in modest doses) is its surrogacy for time-fromdiagnosis. Moreover, neither reducing/stopping levodopa, nor inhibition of its peripheral wastage by co-prescription of a COMT-inhibitor, reduces homocysteine [59].

Anti-nuclear antibody, present in a quarter of probands, was an indicator of the outcome of anti-Helicobacter therapy. Outcome is uncertain in IP even when anti-microbial sensitivities are known/compliance is monitored [23,24]. Gait improves in IP following 'biopsy-proven' $H$. pylori eradication $[18,23,24]$. Here, following anti-Helicobacter therapy, gait deteriorated in the ANA-positive in stark contrast to performance in the ANA-negative. ANA appeared to alert to continuing infection, and might be more sensitive to its detection than examining two biopsies. Bolus antigen release may accentuate deterioration where antiHelicobacter therapy fails. ANA-positivity and a lower 
CD8+ count were intrinsically linked. Reduced cytoxicity may have impaired clearance of residual organisms. Compensation by expression of CD8 on mature CD4+ cells [60] may have failed, even though an increased proportion of such cells (CD4bright+CD8dull+) has been reported in IP as a whole [5,6]. Although NK-activity is stimulated by $H$. pylori in vitro [61], the NK-count was not a prognostic indicator.

The increase, over a decade, in immunoblot-positivity over ELISA-positivity may signify more low-density and occult (gastric lymph node [62]) infection. It may or may not be IP-specific. Association of a higher lymphocyte count with immunoblot-positivity suggests that it represents infection rather than memory. More low-density infection would fit with greater incidental antimicrobial use in a context of impaired bacterial clearance. Propensity to hidden infection/resting (coccoid) forms might be greater where the 'protective' urease continues to produce ammonia in the face of cytokine-driven inhibition of gastric acid [56]. Such progressive hypochlorhydria could explain peptic ulcer being prodromal by decades in IP [26], and the increased likelihood of seropositivity in younger probands [63]. That Helicobacter detected only by molecular-microbiology on gastric biopsies appears to offer the same therapeutic opportunity as does frank infection [18], underlines its relevance to IP. Moreover, persistence at this level following treatment of frank infection appears detrimental [23]. These findings may predicate on an autoimmune response to Helicobacter.

In conclusion, the explanation of the different manifestations of IP between-probands, and within- proband over time, may lay in the interaction between more than one pathogen and determinants, genetic and environmental, of inflammatory response. Helicobacter may be necessary though not sufficient, SIBO a frequent, relatively non-specific and dose-related, player. A viral premonitory phase may prove the common denominator for IP, other 'neurodegenerative' diseases and neuro/psychiatric syndromes and 'functional' gastrointestinal disorders.

\section{Competing interests}

The authors declare that they have no competing interests.

\section{Authors' contributions}

RJD, SMD, AC, ITB, MAAI, RS and DWP designed research; RJD, SMD, ITB, MAAI, TD, AJL, AlC, NLO, JMP, $\mathrm{JB}$ and DWP performed research; CW contributed new analytical tools; AC,RJD, SMD and CW analyzed data; SMD, RJD, CW and AC wrote paper. All have read and approved the final manuscript.

\section{Acknowledgements}

The work was funded initially (Phase I) by the Medical Research Council at the Clinical Research Centre, Harrow, and subsequently (Phase 2) through the Psychiatry Research Trust, London, which received grants from the Hayward Foundation, the Cyril Corden Trust and the Cecil Pilkington Charitable Trust and donations from Brian Newman and Louise Barton. Our grateful thanks go to Dr Robert J Owen, Laboratory of Gastrointestinal Pathogens, Health Protection Agency, London, and Dr Stephen Devereux, Department of Haematology, King's College Hospital, London for supplying contemporaneous control data, and Dr Ron Hutton, What's Driving Parkinson's, Psychiatry Research Trust, for his work on the bibliography.

\section{References}

I. Hung X, Reynolds AD, Mosley RE, Gendelman HE: CD 4+ T cells in the pathobiology of neurodegenerative disorders. I Neuroimmunol 2009, 2 I I:3-15.

2. Perry $\mathrm{VH}$ : Persistent pathogens in the parenchyma of the brain. J Neurovirol 2000, 6(SuppI I):S86-S89.

3. Watkins AD: Perceptions, emotions and immunity: an integrated homeostatic network. Q J Med 1995, 88:283-94.

4. Baba Y, Kuroiwa A, Uitti RJ, Wszolek ZK, Yamada T: Alterations of T-lymphocyte populations in Parkinson disease. Parkinsonism Related Disorders 2005, I I :493-8.

5. Bas J, Calopa M, Mestre M, Molleví DG, Cutillas B, Ambrosio S, Buendia E: Lymphocyte populations in Parkinson's disease and in rat models of parkinsonism. J Neuroimmunol 200I, I I 3:|46-52.

6. Hisanaga $K$, Asagi $M$, Itoyama $Y$, Iwasaki $Y$ : Increase in peripheral CD4 Bright+ CD8 Dull+ T cells in Parkinson's disease. Arch Neurol 200I, 58: I580-3.

7. Martilla RJ, Eskola J, Päivärinta M, Rinne UK: Immune functions in Parkinson's disease. Adv Neurol 1984, 40:315-23.

8. Braak H, de Vos RAl, Bohl J, Del Tredici K: Gastric $\alpha$-synuclein immunoreactive inclusions in Meissner's and Auerbach's plexuses in cases staged for Parkinson's disease-related brain pathology. Neurosc Letters 2006, 396:67-72.

9. Pfeiffer RF: Gastrointestinal dysfunction in Parkinson's disease. Lancet Neurology 2003, 2:107-16.

10. Goldstein DS, Holmes CS, Dendi R, Bruce SR, Li S-T: Orthostatic hypotension from sympathetic denervation in Parkinson's disease. Neurology 2002, 58: I247-55.

II. Olsen JH, Friis S, Frederiksen K: Malignant melanoma and other types of cancer preceding Parkinson disease. Epidemiol 2006, I 7:582-7.

12. O'Neill CJA, Richardson MD, Charlett A, McHugh L, Bowes SG, Purkiss AG, Weller C, Dobbs SM, Dobbs RJ: Could seborrhoeic dermatitis be implicated in the pathogenesis of parkinsonism? Acta Neurol Scand 1994, 89:252-7.

13. Charlett A, Dobbs RJ, Purkiss AG, Weller C, Peterson DW: Cortisol is higher in parkinsonism and associated with gait deficit. Acta Neurol Scand 1998, 97:77-85.

14. Hu G, Jousilahti P, Bidel S, Antikainen R, Tuomilehto J: Type 2 Diabetes and the Risk of Parkinson's Disease. Diabetes Care 2007, 30:842-7.

15. Davis JW, Grandinetti A, Waslien CJ, Ross GW, White LR, Morens DM: Observations on Serum Uric Acid Levels and the Risk of Idiopathic Parkinson's Disease. Am J Epidemiol 1996, I44:480-4.

16. Hu G, Antikainen R, Jousilahti P, Kivipelto M, Tuomilehto J: Total cholesterol and the risk of Parkinson disease. Neurology 2008, 70:1972-79.

17. Dobbs RJ, Charlett A, Purkiss AG, Dobbs SM, Weller C, Peterson DW: Association of circulating TNF- $\alpha$ and IL-6 with ageing and parkinsonism. Acta Neurol Scand 1999, 100:34-4I.

18. Dobbs RJ, Dobbs SM, Weller C, Charlett A, Bjarnason IT, Curry A, Ellis DS, Ibrahim MAA, McCrossan MV, O'Donohue J, Owen RJ, Oxlade NL, Price AB, Sanderson JD, Sudhanva M, Williams J: Helicobacter hypothesis for idiopathic parkinsonism: before and beyond. Helicobacter 2008, I 3:309-22.

19. Abbott RD, Petrovitch H, White LR, Masaki KH, Tanner CM, Curb JD, Grandinetti A, Blanchette PL, Popper JS, Ross GW: Frequency of bowel movements and the future risk of Parkinson's disease. Neurology 200I, 57:456-62.

20. Charlett A, Dobbs RJ, Weller C, Dobbs SM: Stasis in the gut: the source of xenobiotic in idiopathic parkinsonism. Eur J Clin Pharmacol 1997, 52(Suppl): I 68. 
21. Posserud I, Stotzer P-O, Björnsson ES, Abrahamsson H, Simrén M: Small intestinal bacterial overgrowth in patients with irritable bowel syndrome. Gut 2007, 56:802-8.

22. Weller C, Charlett A, Oxlade NL, Dobbs SM, Dobbs RJ, Peterson DW, Bjarnason IT: Role of chronic infection and inflammation in the gastrointestinal tract in the etiology and pathogenesis of idiopathic parkinsonism. Part 3: Predicted probability and gradients of severity of idiopathic parkinsonism based on $\boldsymbol{H}$. pylori antibody profile. Helicobacter 2005, I 0:288-97.

23. Bjarnason IT, Charlett A, Dobbs RJ, Dobbs SM, Ibrahim MAA, Kerwin RW, Mahler RF, Oxlade NL, Peterson DW, Plant JM, Price AB Weller C: Role of chronic infection and inflammation in the gastrointestinal tract in the etiology and pathogenesis of idiopathic parkinsonism. Part 2: Response of facets of clinical idiopathic parkinsonism to Helicobacter pylori eradication. A randomized, double-blind, placebo-controlled efficacy study. Helicobacter 2005, 10:276-87.

24. Dobbs RJ, Dobbs SM, Weller C, Bjarnason IT, Oxlade NL, Charlett A, Al-Janabi MA, Kerwin RW, Mahler RF, Price AB: Role of chronic infection and inflammation in the gastrointestinal tract in the etiology and pathogenesis of idiopathic parkinsonism. Part I: Eradication of Helicobacter in the cachexia of idiopathic parkinsonism. Helicobacter 2005, 10:267-75.

25. Pierantozzi M, Pietroiusti A, Galante A, Sancesario G, Lunardi G, Fedele E, Giacomini P, Scanzione P: Helicobacter pylori-induced reduction of acute levodopa absorption in Parkinson's disease patients. Ann Neurol 2001, 50:686-7.

26. Strang RR: The association of gastro-duodenal ulceration with Parkinson's disease. Med J Austr 1965, 52:842-3.

27. Lundgren A, Suri-Payer E, Enarsson K, Svennerholm A-M, Lundin BS Helicobacter pylori-specific CD4+CD25 high regulatory Tcells suppress memory $\mathrm{T}$-cell responses to Helicobacte pylori in infected individuals. Infect Immun 2003, 7 I: I755-62.

28. Schmees C, Prinz C, Treptau T, Rad R, Hengst L, Voland P, Bauer S, Brenner L, Schmid RM, Gerhard M: Inhibition of T-Cell Proliferation by Helicobacter pylori gamma-Glutamyl Transpeptidase. Gastroenterology 2007, I32:|820-33.

29. Dobbs RJ, Dobbs SM, Charlett A, Weller C: Downward shift in serum IgM with Helicobacter pylori seropositivity. I Infection 2000, 41:240-4

30. Emilia G, Luppi M, Zucchini P, Morselli M, Potenza L, Forghieri F, Volzone F, Jovic G, Leonardi G, Donelli A, Torelli G: Helicobacter pylori and chronic immune thrombocytopenic purpura: longterm results of bacterium eradication and association with bacterium virulence profiles. Blood 2007, I I 0:3833-4 I.

31. Barroso N, Campos Y, Huertas R, Esteban J, Molina JA, Alonso A, Gutierrez-Rivas E, Arenas J: Respiratory chain enzyme activities in lymphocytes from untreated patients with Parkinson disease. Clin Chem 1993, 39:667-9.

32. Calne DB, Snow BJ, Lee C: Criteria for diagnosing Parkinson's Disease. Ann Neurol 1992, 32(Suppl): I25-7.

33. Kirollos C, O'Neill CJA, Dobbs RJ, Charlett A, Bowes SG, Purkiss AG, Hunt WB, Dobbs SM: Quantification of the cardinal signs of parkinsonism and of associated disability in spouses of sufferers. Age Ageing 1993, 22:20-6.

34. Amadori A, Zamarchi R, De Silvestro G, Forza G, Cavatton G, Danieli GA, Clementi M, Chieco-Bianchi L: Genetic control of the CD4 CD8 T-cell ratio in humans. Nature Med 1995, I 2:1279-83.

35. Bland JM, Altman DG: Statistical methods for assessing agreement between two methods of clinical measurement. Lancet 1986, I:307-317.

36. Pimentel M, Chow EJ, Lin HC: Normalisation of lactulose breath testing correlates with symptom improvement in irritable bowel syndrome. A double-blind, randomized, placebo-controlled study. Am / Gastroenterol 2003, 98:412-9.

37. Rhodes JM, Middleton P, Jewell DP: The lactulose hydrogen breath test as a diagnostic test for small-bowel bacterial overgrowth. Scand J Gastroenterol 1979, I 4:333-6.

38. Bland M: Chapter I5, Clinical Measurement. In An Introduction to Medical Statistics Oxford: University Press; 2000:268-93.

39. von Campenhausen S, Bornschein B, Wick R, Bötzel K, Sampaio C, Poewe W, Oertel W, Siebert U, Berger K, Dodel R: Prevalence and incidence of Parkinson's disease in Europe. Eur Neuropsychopharmac 2005, I 5:473-90.

40. Hoehn MM, Yahr MD: Parkinsonism: onset, progression and mortality. Neurology 1967, 17:427-42.
4I. Lazzerini PE, Capecchi PL, Selvi E, Lorenzini S, Bisogno S, Galeazzi M, Pasini FL: Hyperhomocysteinemia, inflammation and autoimmunity. Autoimmunity Rev 2007, 6:503-9.

42. Lanier LL: Evolutionary struggles between NK cells and viruses. Nature Rev Immunol 2008, 8:259-68.

43. Fordyce $C B$, Gagne D, Jalili F, Alatab S, Arnold DI, Da Costa D, Sawoszczuk S, Bodner C, Shapiro S, Collet JP, Robinson A, Le Crugel JP, Lapierre Y, Bar-Or A, Trojan DA: Elevated inflammatory markers in post-poliomyelitis syndrome. J Neurol Sci 2008 , 27I:80-6.

44. Gawne AC, Wells KR, Wilson KS: Cardiac risk factors in polio survivors. Arch Phys Med Rehabil 2003, 84:694-6.

45. Nielsen NM, Wohlfahrt J, Aaby P, Hjalgrim H, Pedersen CB, Askgaard DS, Melbye $M$ : Cancer risk in a cohort of polio patients. Int Cancer 2001, 92:605-8.

46. Nielsen NM, Rostgaard K, Hjalgrim H, Aaby P, Askgaard D: Poliomyelitis and Parkinson's disease. JAMA 2002, 287:I650-I.

47. Martyn CN, Barker DJP, Osmond C: Motorneurone disease and past poliomyelitis in England and Wales. Lancet 1988 , I: $1319-22$.

48. Swingler RJ, Fraser H, Warlow CP: Motor neuron disease and polio in Scotland. J Neurol Neurosurg Psychiatry I 992, 55: I I I 6-20.

49. Weller C, Nicholson PW, Dobbs SM, Bowes SG, Purkiss A, Dobbs RJ: Reduced axial rotation in the spouses of sufferers from idiopathic Parkinsonism. Age Ageing 1992, 2 I: 189-94.

50. Kirollos C, Charlett A, O'Neill CJA, Kosik R, Mozol K, Nicholson PW, Hunt WB, Weller C, Dobbs SM, Dobbs RJ: Objective measurement of activation of rigidity: diagnostic, pathogenetic and therapeutic implications in parkinsonism. Brit J Clin Pharmacol 1996, 41:557-64.

5I. Drossman DA: The functional gastrointestinal disorders. Diagnosis, pathology, and treatment-A multinational consensus. Boston: Little, Brown and Co; 1994.

52. Kett K, Brandtzeag P, Radl J, Haaijman J]: Different subclass distribution of IgA-producing cells in human lymphoid organs and various secretory tissues. J Immunol 1986, I 36:363 I-35.

53. Webster DD, Mortimer JA: Failure of L-dopa to relieve activated rigidity in Parkinson's disease. In Advances in experimental medicine and biology. Parkinson's disease: neurophysiology, clinical and related aspects Volume 90 . Edited by: Messiha FS, Kenny AD. New York: Plenum; 1977:297-312.

54. Seshadri S, Beiser A, Selhub J, Jacques PF, Rosenberg IH, D'Agostino $\mathrm{RB}$, Wilson PWF, Wolf PA: Plasma homocysteine as a risk factor for dementia and Alzheimer's disease. N Engl J Med 2002, 346:476-83.

55. Tiemeier H, van Tuijl HR, Hofman A, Meijer J, Kiliaan AJ, Breteler MM: Vitamin BI2, folate and homocysteine in depression: the Rotterdam study. Am J Psychiatry 2002, I 59:2099-I0I .

56. El-Omar EM: The importance of interleukin $I \beta$ in Helicobacter pylori associated disease. Gut 200I, 48:743-7.

57. Wahner AD, Sinsheimer JS, Bronstein JM, Ritz B: Inflammatory cytokine gene polymorphisms and increased risk of Parkinson disease. Arch Neurol 2007, 64:836-40.

58. Caccamo D, Gorgone G, Curro M, Parisi G, Di lorio W, Menichetti C, Belcastro V, Parnetti L, Rossi A, Pisani F, lentile R, Calabresi P: Effect of MTHFR polymorphisms on hyperhomocysteinemia in levodopa-treated Parkinsonian patients. NeuroMolecular Med 2007, 9:249-54.

59. O'Sulleabhain PE, Bottiglieri T, Dewey RB, Sharma S, Diaz-Arrastia R Modest increase in plasma homocysteine follows levodopa initiation in Parkinson's disease. Movement disorders 2004, 19:1403-8.

60. Parel Y, Chizzolini C: CD4+ CD8+ double positive (DP) T cells in health and disease. Autoimmunity Rev 2004, 3:2 I 5-20.

61. Tarkkanen J, Kosunen T, Saksela E: Contact of lymphocytes with Helicobacter pylori augments natural killer cell activity and induces production of gamma interferon. Infect Immunity I993, 6I:3012-6.

62. Ito T, Kobayashi D, Uchida K, Takemura T, Nagaoka S, Kobayashi I, Yokoyama T, Ishige I, Ishige $Y$, Ishida $N$, Furukawa A, Muraoka $\mathrm{H}$, lkeda S, Sekine M, Ando N, Suzuki Y, Yamada T, Suzuki T, Eishi Y: Helicobacter pylori invades the gastric mucosa and translocates to the gastric lymph nodes. Lab Investigation 2008 , 88:664-8I. 
63. Dobbs RJ, Charlett A, Dobbs SM, Weller C, Peterson DW: Parkinsonism: differential age-trend in Helicobacter pylori antibody. Aliment Pharmacol Ther 2000, 14:1199-205.

64. Beck AT, Beamesderfer A: Assessment of depression: the depression inventory. In Psychological measurements in psychopharmacology, 7, Modern problems in psychiatry Edited by: Pichot T. Basel: Karger; | 974:15I-9.

65. Denham MJ, Jefferys P: In Source book of geriatric assessment Volume 2. Hampshire: Karger; 1984:52.

66. Folstein MF, Folstein SE, McHugh PR: Mini-mental state. A practical method for grading the cognitive state of patients for the clinician. J Psychiat Res 1995, I 2:189-98.

67. Webster DD: Clinical analysis of the disability of Parkinson's disease. Mod Treatments 1968, 5:257-282.

Publish with Bio Med Central and every scientist can read your work free of charge

"BioMed Central will be the most significant development for disseminating the results of biomedical research in our lifetime. "

Sir Paul Nurse, Cancer Research UK

Your research papers will be:

- available free of charge to the entire biomedical community

- peer reviewed and published immediately upon acceptance

- cited in PubMed and archived on PubMed Central

- yours - you keep the copyright
BioMedcentral 